\title{
EL LITORAL SUD-VALENCIÀ A LA CARTOGRAFIA OFICIAL (SEGLES XIX I XX)
}

\author{
Vicenç M. Rosselló i Verger \\ Departament de Geografia.Universitat de València
}

\section{RESUM}

La cartografia oficial dels segles XIX i Xx es concentra en la Dirección de Hidrografía per a les cartes nàutiques i l'Instituto Geográfico per als mapes topogràfics. Els dos organismes, un controlat per la Marina, i l'altre, dirigit alternativament per enginyers militars o civils, no tingueren mai cap tipus de coordinació. L'anàlisi de les sèries concernents al litoral del migjorn del País Valencià demostra una manca de continuïtat de criteris de selecció de dades i de semiologia. Si la cartografia nàutica va assolir una gran categoria a final del Vuit-cents, a partir del segle xx, va caure en inoperància. Altrament, la de l'Instituto Geográfico ha millorat notablement. Un cop d'ull al registre toponímic ho demostra.

Paraules clau: litoral, País Valencià, cartografia, relleu litoral, toponímia.

\section{ABSTRACT}

The sud-valencian coastline in the official cartography (19th and 20th centuries)

The official cartography from the 19th and 20th centuries gathers at the Dirección de Hidrografía (nautical charts), and at the Instituto Geográfico (topographic maps). Both organizations, the former controlled by the Navy, and the latter alternatively managed by military and civil engineers, never coordinated themselves. The analysis of a series of documents concerning the south coastline of theValencia Land shows a lack of continuity of criteria with regard to the selection of data and semiology. Although the nautical cartography achieved great ranking at the end of the 19th century, in the 20th century it fell into uselessness. On the other hand, the Instituto Geográfico cartography has improved considerably. Just a look at the toponymic register proves it.

Keywords: littoral, Valencia Land, cartography, coastal relief, toponimy. 
Oficial té ara un sentit que per ventura no hauria estat entès a final del segle XVIII quan Tomás López de Vargas maldava per enllestir el factici Atlas geographico del Reyno de España que consumaren els seus fills, o Vicente Tofiño de San Miguel publicava l'Atlas marítimo com a complement dels Derroteros. La cartografia nàutica, des de l'Observatorio de San Fernando a Cadis, fundat pel valencià Jordi Joan i Santacília, va assajar una pristina sistematització abans de l'empenta organitzadora dels liberals progressistes. Ara i ací em concentraré en dos organismes que sorgeixen precisament en aquells moments, la Dirección de Trabajos hidrográficos i l'Instituto Geográfico, tot i que no fructificarien -pel que fa al territori que ens ocupa-fins al temps de la Restauració. Les vicissituds polítiques posteriors no impediren que l'armada mantingués sempre el control de les cartes de navegar mentre que la cartografia terrestre, segons que comandaren els conservadors o els liberals, dependria de l'exèrcit o dels enginyers i/o geòmetres més o menys civils. La guerra dels tres anys va trencar una executòria digna -en alguns moments brillant- amb el col-lapse conseqüent. Cal dir, tanmateix, que les costes estaven més ben representades que no les nostres terres, gairebé oblidades pels cartógrafs oficials fins a mitjans Nou-cents.

\section{LES CARTES NÀUTIQUES}

L'Atlas de Tofiño va aparèixer el 1778, però l'activitat hidrogràfica governamental s'orientaria més tost a l'aixecament de cartes nàutiques de les Filipines i Amèrica ja que aleshores Espanya es considerava una potència marítima. L'Hydrographical Office britànic fou establert el 1795 i la Dirección de Trabajos Hidrográficos -o més curt, de Hidrografía- fou fundada el 1797 per José Espinosa que poc després hi associà Felip Bauzà. La Dirección de Hidrografía fou l'única institució estatal dedicada a la producció de mapes fins a la creació (1853) de la Dirección de la Carta geográfica de España (González i Martín, 2003).

El Portulano de la península de España, projectat a Cadis el 1813, preveia un segon quadern dedicat als regnes de València i Múrcia. El responsable de la Dirección de Hidrografía, Felip Bauzà (1815-1823) va comunicar al ministre, el 1816, que prosseguia el portolà, començat per Catalunya i continuant per les costes valencianes. Els deu plànols sense data -assignats a 1813 pel catàlegcorresponen probablement als anys posteriors a 1816 i pertanyen a l'esmentat quadern segon (núms. 19-28). Són els següents: Dénia, Xàbia, Moraira, la Fossa de Calp, Calp, Altea, Benidorm, badia d'Alacant, illa de Tabarca i Torrevieja. Els formats no són regulars, l'escala gràfica va en milles (predominen les numèriques entorn d' $1 / 20.000$, no expressades mai) i les sondes són consignades en braces o peus castellans. 
Felip Bauzà -que tenia la idea i propugnava un projecte global de construir un mapa d'Espanya on confluïssen els interessos marítims i els territorials o geogràfics- havia estat nomenat, justament l'any 1823, «para el levantamiento de la carta de España». La capgirada absolutista i condemna a mort l'obligaren a exiliar-se a Londres. El seu successor Martín Fernández Navarrete (1823-1844) no va fer res que ens interesse. A la segona meitat del segle XIx, les activitats hidrogràfiques s'acceleraran per assolir una època daurada.

El període 1854-1908 abasta la coincidència de la Dirección de Hidrografía i del Depósito Hidrográfico, però quant al nostre afer, ho podem centrar en l'anomenada Comisión Hidrográfica de la Península que començaria a funcionar el 1860, tot i que corresponia a una idea proposada anteriorment. El 1859, l'acabada de crear Comisión de Estadística general del Reino assumí competències al ram hidrogràfic, però l'armada es resistí i guanyà la partida. Al costat de les comissions americanes i filipines, va sorgir la peninsular (que també atenyia les Illes), centrada en el vapor Piles i la seua oficialitat. Una de les primeres missions pretenia la triangulació de tres ordres, al marge de la de l'Instituto Geográfico; hom adquirí aparells geodèsics i, el 1862, enrolà l'alferes Rafael Pardo de Figueroa, futur protagonista de la cartografia editada. El va precedir al comandament José Montojo (1864-1876) que, malgrat la inestabilitat política, va poder engegar la maquinària. El 1867 ja havia amidat la base a Sanlúcar de Barrameda i va triangular la costa fins als Alfacs de l'Ebre: s'imposava el sentit antihorari.

Durant el pilotatge de Pardo (1877-1887), l'activitat va retre més i amb major rigor en la formulació - mètode de Hansen- composta per 42 triangles de 60 i $40 \mathrm{~km}$ de costat, establerts entre 1872 i 1876 i verificats amb instrumental nou i més precís i l'ajuda del vapor auxiliar Gaditano. El 1876, des de Roquetas (Almería), la malla geodèsica havia arribat al Montsià, però Pardo optà per una nova base al delta de l'Ebre ('Ampolla, 1879):

... la parte de las costas para el mapa que levanta el Instituto Geográfico va a ser tomada de los trabajos de la Marina, que por tanto deben ser suficientemente exactos para el objeto. (Carta AGM, DH, AP, leg. 4937. 14 de juliol de 1884 citada per González i Martín, 2003).

E1 1891 calculà la diferència de longitud entre València i l'Observatorio de San Fernando amb el telègraf que rebia el senyal del vapor Piles. La determinació de latitud $\mathrm{i}$ azimut es verificà el $1878 \mathrm{a}$ València.

La producció cartogràfica d'aquest període -que és la substancial ací analitzada- la veurem després; avancem, però, que juga sobretot amb les escales de llarg abast (1/100.000 i 1/50.000), en contraposició als plànols de ports o sorgidors, més detallats en les sondes i la naturalesa del fons.

E1 1908, la nova Direcció general de Navegación y Pesca que arribà a tenir una Sección de Hidrografía, arrossegava el pessimisme de la fallida del 1898. 
Tant que aconsellava recórrer a les cartes nàutiques estrangeres. La imatge internacional de la cartografia nàutica espanyola s'havia deteriorat i el Servicio Hidrográfico de la Armada, creat el 1927 sota la dictadura, no arribaria a restablir-la ni de molt. L'Instituto Hidrográfico de la Marina de la postguerra civil (1944) encara treia edicions esmenades de les velles planxes calcogràfiques fins als anys seixanta del segle xx. La substitució posterior -que hauria d'haver millorat técnicament- va ser vacil·lant i d'escassa categoria tipogràfica.

\section{Els documents sud-valencians}

La carta N. ${ }^{\circ} 286 .{ }^{1}$ Mar Mediterráneo. Costa S.E. de España. Plano del Puerto y Ciudad de Alicante $(62 \times 45 \mathrm{~cm} ; 1 / 3.000)$ duu com a peu: Madrid, Almirantazgo, Sección de Hidrografía, 1869. La construcció és deguda a Josep Riudavets, oficial de marina menorquí que ens trobarem sovint, i el gravat és de P. Hortigosa. Les més de 400 sondes consten en metres. Aquesta carta tingué vigència fins al 1878 quan la substituteix la 286A. Un projecte de port o trencaones que hi figura mai no arribà a existir. (685 al catàleg de CANO, 2003).

La primera intervenció de R. Pardo es va centrar en els plànols de detall dels ports, fondeaderos i surgideros, tot seguint la tònica del seu predecessor $\mathrm{J}$. Montojo amb el qual signa la carta N..$^{\circ} 285 \mathrm{~A}$. Mar Mediterráneo. Costa Sueste de España. Plano de la Bahía de Santa Pola y de las Isla de Tabarca. (936 x $614 \mathrm{~mm}$; 1/25.000 ca). L'aixecaren a mitges, el 1876, José Montojo y Salcedo i Rafael Pardo de Figueroa; el dibuix era de Josep Riudavets i Tudury i el gravat d'E. Pérez. Duu el peu de Madrid, Depósito de Hidrografía, 1877 i una escala gràfica de $3.000 \mathrm{~m}$ i 3 milles, a més de les isòbates de $-5 \mathrm{i}-10 \mathrm{~m}$. Va ser corregida, almenys, el 1888 i 1902. (906 al catàleg de CANO, 2003). El mateix any, sortirien unes altres dues cartes aixecades l'anterior sota la direcció de R. Pardo: Benidorm i Moraira. Carta N. ${ }^{\circ} 287$ A. Mar Mediterráneo. Costa S.E. de España. Plano de la Ensenada de Benidorme. 471 x 308 mm; 1/16.700 ca). Madrid, 1877. Escala gràfica de $2.000 \mathrm{~m}$ i 1 milla. El dibuix és de J. Riudavets $\mathrm{i}$ el gravat d'I. Tubau. Porta la isòbata de $-10 \mathrm{~m}$ i centenars de sondes. (Catàleg Cano, 2003: 907). La Carta N. ${ }^{\circ}$ 712. Mar Mediterráneo. Costa S.E. de España. Plano de la Ensenada de Morayra. Madrid, 1877 (298 x 459 mm; 1/12.000 ca) duu isòbates de $-10 \mathrm{i}-20 \mathrm{~m}$ i, més de 300 sondes. El gravat és d'E. Fungairiño. (Catàleg Cano, 2003: 908).

L'equip de R. Pardo i J. Riudavets tragué, el 1878, quatre cartes més, aixecades el 1876. Els gravadors canvien i rivalitzen en qualitat: I. Tubau, E. Fungairiño i E. Pérez. Aquests documents duen al catàleg esmentat els números 937, 938, 939 i 953. Carta N. ${ }^{\circ}$ 286A. Mar Mediterráneo. Costa S.E. de España.

1. Aquesta numeració sembla que fou introduïda posteriorment. 


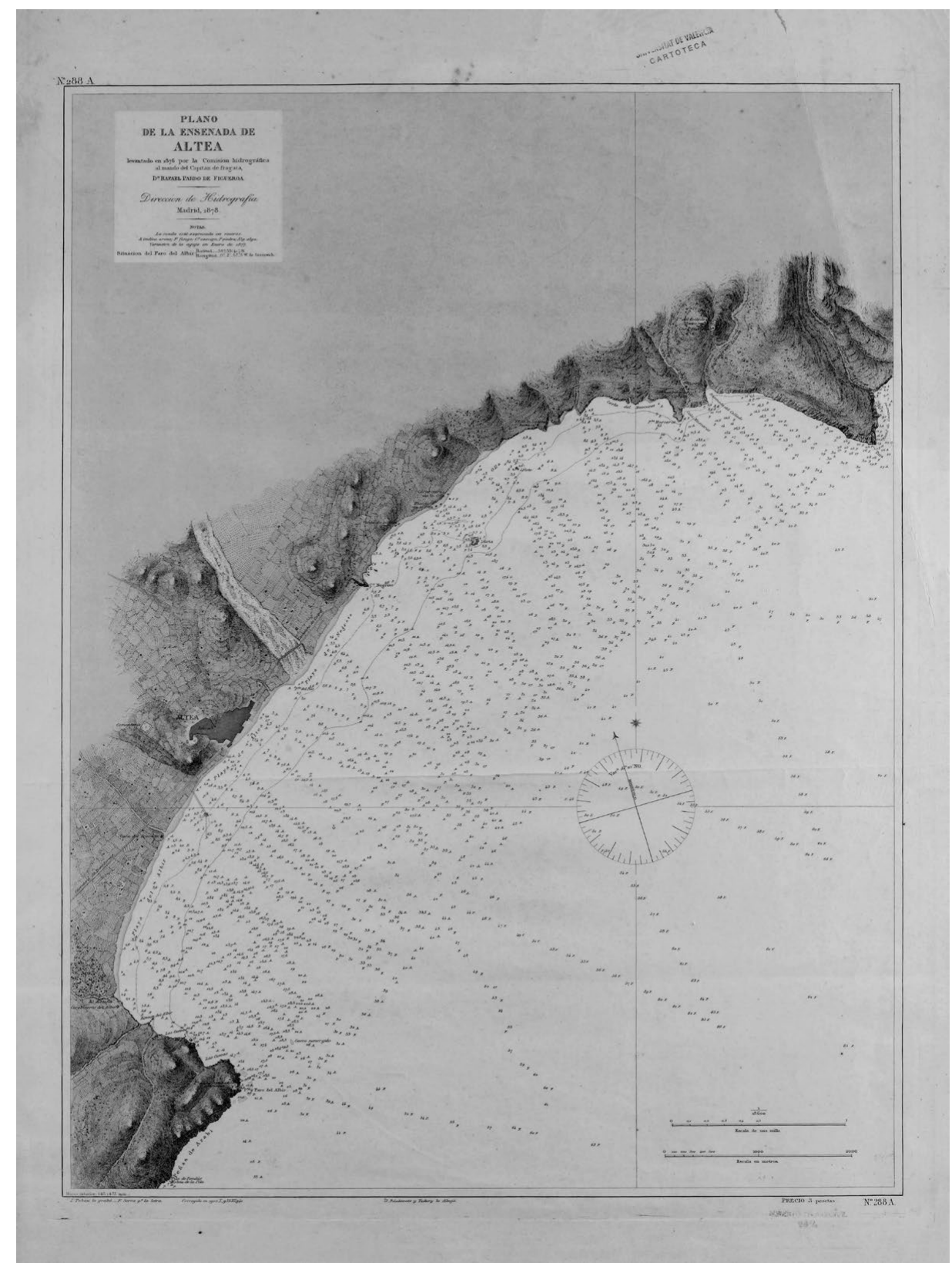

Figura 1. La carta 288A (1878) de la Comisión Hidrográfica: Plano de la Ensenada de Altea a 1/18.600 ca. El disseny és de J. Riudavets i el gravat d'I. Tubau, dirigits per R. Pardo. 
Plano de la Rada y Puerto de Alicante. Madrid, 1878 (61 x 93 cm; 1/5.000). Corregida entre 1902 i 1960, consigna diversos projectes portuaris. Isòbata de $-5 \mathrm{~m}$, dragatges especificats i sondes abundants. La Carta N. ${ }^{\circ} 288 \mathrm{~A}$. Plano de la Ensenada de Altea. Madrid, 1878 (645 x 475 mm; 1/18.600). La primera correcció és de 1902 i l'última, de 1941. Duu una gran densitat de sondes i les isòbates de $-5 \mathrm{i}-10 \mathrm{~m}$. El relleu de la faixa litoral és resolt amb una mena de normals o hachures gravades de forma magistral. La Carta N. ${ }^{\circ} 289 \mathrm{~A}$. Mar Mediterráneo. Costa E. de España. Plano de los fondeaderos de Calpe. Madrid, 1878 (63 x $46 \mathrm{~cm} ; 1 / 16.900)$. Té una escala gràfica d'1 milla i $2.000 \mathrm{~m}$. El relleu de la faixa litoral segueix la pauta anterior amb normals i ombres que accentuen les barrancades. Finalment, la Carta N. ${ }^{\circ}$ 729. Mar Mediterráneo. Costa S.E. de España. Plano de la Rada de Villajoyosa. Madrid, 1878 (39 x $27 \mathrm{~cm} ; 1 / 10.000)$ és d'un gravat exquisit que fou corregit, almenys, els anys 1902, 1906 i 1928. Dos anys després de l'aixecament de R. Pardo i J. Riudavets, eixien a la llum dues cartes de detall més, numerades al catàleg 978 i 979. La Carta N. $^{\circ} 292 \mathrm{~A}$. Mar Mediterráneo. Plano de las ensenadas de Jávea y Portichol. Madrid, 1879 $(496$ x $657 \mathrm{~mm} ; 1 / 13.000 \mathrm{ca})$ duu grafiada la isòbata $-10 \mathrm{~m}$ i correccions de 1883, 1931 i 1944. L'altra Carta N. ${ }^{\circ} 293$ A. Mar Mediterráneo. Costa oriental de España. Plano del Puerto de Denia. Madrid, 1879 (600 x 916 mm; 1/10.000) està corregida i reimpresa vuit vegades entre 1892 i 1939. Les isòbates són confuses a causa dels diversos placers que entrebancaven el port. Encara romania sense publicar la darrera carta aixecada per Pardo i Riudavets, el 1881, que va gravar C. Galván com a resultat de la susdita campanya. Es tracta de la Carta N. ${ }^{\circ}$ 284.A Mar Mediterráneo. Costa S.E. de España. Plano de la Rada de Torrevieja. Madrid, 1883 (657 x $670 \mathrm{~mm} ; 1 / 13.350)$, corregida, almenys, els 1887 i 1935. Porta les isòbates $-5 \mathrm{i}-10 \mathrm{~m}$.

Cal anotar, de tota manera, que tots els plànols o les cartes de detall d'aquesta tongada-Comisión Hidrográfica de la Península-repeteixen les que ja havien estat publicades el 1813 o 1816: els criteris utilitaris eren els mateixos; els mitjans tècnics, molt més precisos.

La sèrie de cartes de llarg abast a 1/100.000, gestada entre 1864 i 1876, va ser naturalment més laboriosa i compromesa. Les que ens afecten, en sentit antihorari, porten la numeració VI-IX i són degudes a l'equip de la Comisión, dirigit per J. Montojo, la primera, i R. Pardo, la resta, sempre amb l'execució de Josep Riudavets i el gravat d'E. Pérez y Pérez. La primera, l'aixecà el capìtà Montojo, el 1876: Carta N. ${ }^{\circ}$ 712. Mar Mediterráneo. Costa Sueste de España. Hoja VI. Desde la Punta de Calnegre hasta Cabo Roig. Madrid, 1877 (Catàleg 926). La segona Carta N. ${ }^{\circ} 832$. Mar Mediterráneo. Costa Sueste de España. Hoja VII. Desde Cabo Roig hasta el Cabo de las Huertas. Madrid, 1888. (937 x $589 \mathrm{~mm}$ ) va trigar 10 o 12 anys en ser publicada i seria corregida, el $1946 \mathrm{i}$ 1960 (Catàleg, 1161). Ambdues porten nombroses sondes amb l'especificació 
de la naturalesa del fons i les isòbates de $-10 \mathrm{i}-30 \mathrm{~m}$. Les eminències del relleu prelitoral que serveixen de senyes porten el topònim i l'altitud en metres. El mateix any 1888, es publicaren els dos fulls restants quan ja havia pres el relleu a la Comisión Hidrográfica de la Península José Gómez Ímaz. Pardo havia deixat enllestida la tasca des de Cabo Roig fins a Roses. Al catàleg (Cano, 2003) figuren amb els números 1162 i 1163 les dues darreres de R. Pardo. La Carta N. 833 Mar Mediterráneo. Costa Sueste de España. Hoja VIII. Desde Cabo de las Huertas hasta el Cabo de San Antonio. Madrid, 1888 (937 x 590 mm), l'havien aixecat els 1876-1877 i la gravà E. Fungairiño. Segueix la pauta batimètrica de les anteriors i fou corregida fins a l'any 1963. La Carta N. ${ }^{\circ} 834$. Mar Mediterráneo Costa Oriental de España. Hoja IX. Desde el Cabo de San Antonio hasta la Albufera de Valencia. Madrid, 1888 (936 x 589 mm), aixecada el 1877 i gravada per C. Galván, repeteix les característiques anteriors i, amb correccions, estigué vigent fins al 1963.

Els quatre grans fulls en projecció Mercator d'escala aproximada a 1/100.000 foren corregits i posats al dia, com hem vist, fins als 1960 i serien al capdavall suplantats el 1963. No he tingut accés al full 712 Desde Calnegre a Cabo Roig, el VIè de la sèrie antiga, però deduesc que ha de ser igual de deplorable que els altres tres que ens ocupen, produits d'una forma apressada i matussera que desmunta una bona tradició assolida més de mig segle abans.

La revisió del full 832 Desde Cabo Roig a Cabo de la Huerta es va fer sobre la 3. ${ }^{a}$ edició de 1996, corregida el 1997. ${ }^{2}$ L'afany d'adaptar la carta al model internacional, acolorits en groc, el continent, $i$ en blau, la mar, ha contribuit a un producte anodí i de magra qualitat tipogràfica. Incorpora, com a novetat, isohipses amb equidistància de $100 \mathrm{~m}$ i nombroses isòbates de $-5 \mathrm{a}-1.000 \mathrm{~m}$. Del deplorable full 833 Desde el Cabo de las Huertas al Cabo de San Antonio, només he vist la 1. a edició (1963), corregida el 1992, que manté l'escala aproximada a 1/100.000. L'únic topònim millorat és Benidorm i el relleu matusser és representat per falses ortogonals. Les isòbates inscrites són les de $-20 \mathrm{i}-50 \mathrm{~m}$. El full 834 Desde Cabo de San Antonio a la Albufera (1963) va substituir amb el nou model la carta a 1/100.000, afegint-hi les isohipses amb $80 \mathrm{~m}$ d'equidistància a la faixa litoral, almenys en la 2. ${ }^{\mathrm{a}}$ edició de 1991, corregida el 1997. ${ }^{3}$ Les isòbates hi van de $-5 \mathrm{a}-100 \mathrm{~m}$, però l'exemplar duu menys sondes que la carta de 1877. I, per descomptat, menys topònims.

\section{EL MAPA TOPOGRÁFICO NACIONAL}

Malgrat el títol que va assumir Tomás López de Vargas com a «Geógrafo de los Dominios de S.M.», el seu Mapa geográfico del Reyno de Valencia de 1788

2. La 1. i i la 2. a són de 1963 i 1990.

3. El 1987 va eixir la 6. impressió, amb correccions, p.e., de la declinació. 
$(910 \times 1.005 \mathrm{~mm} ; 1 / 340.000 \mathrm{ca})$ no pertany a una sèrie homogènia i mai no va aconseguir ser considerat com a oficial. Per altra banda, els esforços del marí i polític liberal Felip Bauzà d'unificar la cartografia terrestre i marítima no varen reeixir. Podríem qualificar d'oficiós l'assaig de l'enginyer militar, Francisco Coello de Portugal per sistematitzar el mapa de les províncies espanyoles (Atlas de España y sus posesiones de Ultramar), com a acompanyament del Diccionario geográfico-estadístico-histórico de España y sus posesiones de Ultramar (1845-1850) del seu correligionari Pasqual Madoz. El projecte es va beneficiar de la recol· lecció de Bauzà, dels documents del Depósito de la Guerra i d'altres d'origen francès. La sèrie inconclusa constava de mapes a 1/200.000 en projecció Bonne i coordenades basades al meridià de Madrid, amb una mena de corbes de configuració del relleu, tot burinat sobre planxa d'acer de gran qualitat. El full d'Alicante (1859) té 73 x $99 \mathrm{~cm}$, porta nombroses sondes -que en denoten la font-i fou gravat per C. Leclerq (contorn) i A. Lebreton (toponímia).

Deixem a banda els mapes militars seriats, diferents del topogràfic, que ja adoptaren les escales redones d'1/500.000, 1/200.000 i 1/100.000, entre $1881 \mathrm{i}$ la primera guerra mundial (Rosselló, 2008), per concentrar l'atenció en el fonamental Mapa Topográfico Nacional a 1/50.000, projectat el 1870, i les col·leccions connexes, de vegades impreses amb anterioritat.

La concepció del mapa estatal oficial a una generosa escala d'1/50.000 implicava, a mitjan segle xIx, una exigència luxosa i cara (Urteaga i Nadal, 2001). La fiscalitat dels reformistes liberals demanava escales detallades i més planimetria per confegir un cadastre satisfactori que, el 1936, encara no existia. L'exèrcit, en canvi, anteposava el relleu de posicions i cotes. Si hi afegim les contradiccions internes dels polítics de la restauració - que, de fet, engegarien la publicació dels fulls-, arribaríem a entendre la successió d'organismes: Instituto Geográfico, creat el 12.09.1870, Instituto Geográfico y Estadístico (1873), Instituto Geográfico y Catastral (1925) i, ara, Instituto Geográfico Nacional. ${ }^{4}$ Simplificant molt, els liberals progressistes ho volien en mans de civils i els conservadors, en mans militars.

L'execució de la malla geodèsica de 1er i 2on ordre s'havia avançat els 18541859 , però la xarxa definitiva no fou enllestida fins a 1915 , cosa que no impedia que les minutes municipals a 1/25.000 anassin cobrint el territori. ${ }^{5}$ Altrament, el 1868, s'estava fixant la nivellació de precisió a Alacant i Cartagena, però entre 1870 i 1872, hom va preferir la d'Alacant, concretament a la façana de l'Ajuntament: 3,4905 m s.n.m.

4. Noteu que geográfico assumeix -com en el segle xvIII- les connotacions de 'cartogràfic'.

5. Aquestes minutes solen duplicar-se, una planimètrica que té més interès fiscal i toponímic $\mathrm{i}$ una altimètrica amb isohipses de 10 en $10 \mathrm{~m}$ i cotes establertes amb la xarxa de 3 er ordre. 


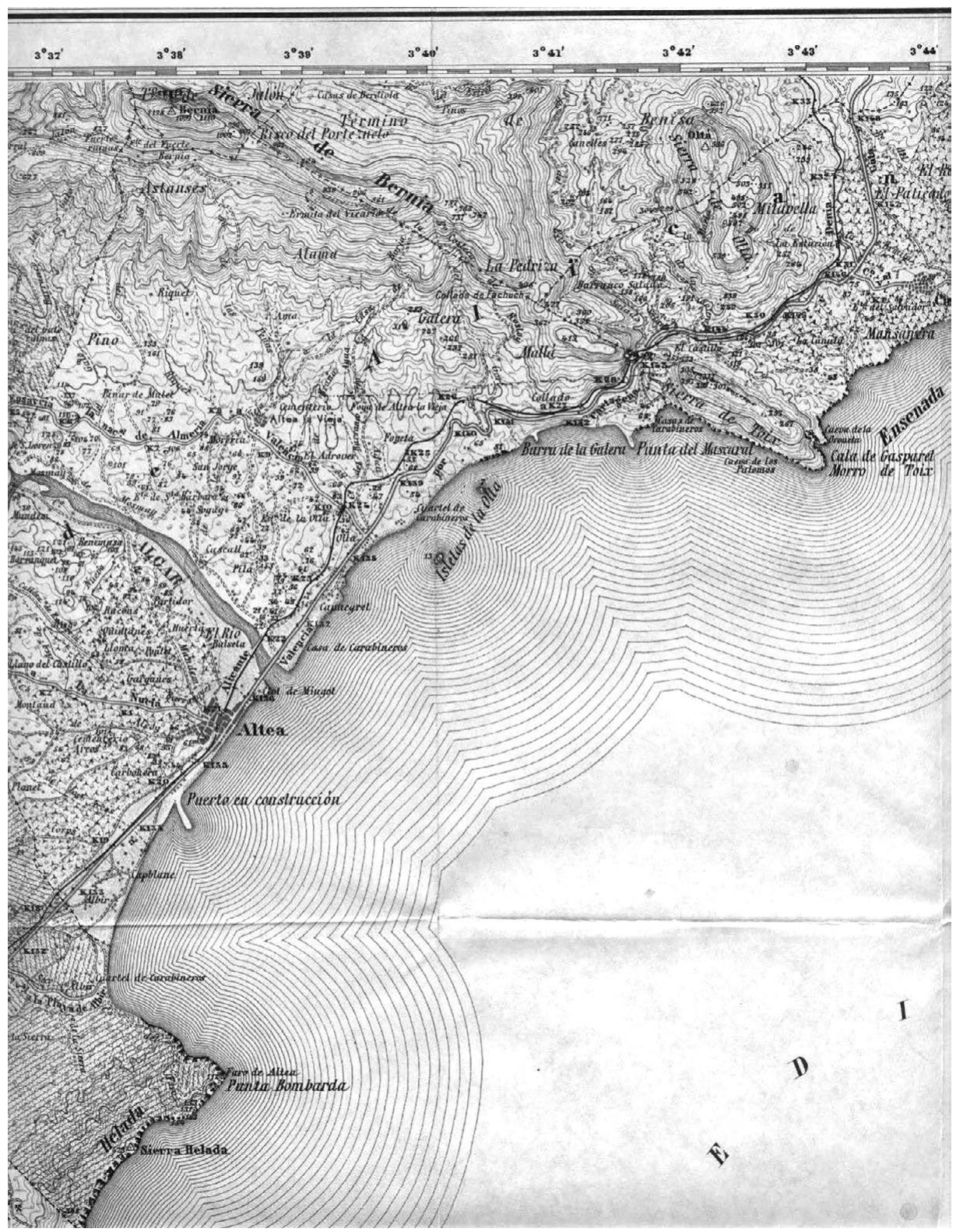

Figura 2. El full 848 (1952) del Mapa Topográfico Nacional, Altea, corresponent a la primera edició 
El plantejament dels 1.114 fulls del MTN és ben conegut. Abasten 20' de longitud i 10' de latitud -que vénen a ser una superfície aproximada de 50 × 70 $\mathrm{cm}$ - en una projecció polièdrica sobre l'el-lipsoide de Struve. El relleu es representa amb corbes de $20 \mathrm{~m}$ d'equidistància. Des de 1915 la impressió va recórrer, en lloc de la litografia, a l'heliogravat en coure a partir de la fotomecànica que va augmentar la qualitat, però no la legibilitat. Les normes de recol· lecció, transcripció i selecció de la toponímia no arribarien fins al 1964!

La marxa de l'edició, començada of course amb el full 559 Madrid, el 1875, va ser molt lenta, sobretot tenint en compte que les minutes valencianes més antigues daten de 1905. Quan, el 1923, Primo de Rivera militaritzà l'Instituto, al sud del paral·lel $42^{\circ}$ només hi havia planimetria; a tot el «Levante» mancava l'altimetria. El 1931, amb la república, tornen a fer-se'n càrrec els civils. El primer full valencià publicat, 935 Torrevieja, va eixir el 1928; dels litorals, el seguí el 914 Guardamar del Segura, el 1933, mentre s'estava proveint d'altimetria el 872 Alicante (1937) gràcies a un vol fotogramètric de dos anys abans; fou publicat el 1940, un cop acabada la guerra. Els altres fulls foren elaborats mitjançant fotogrametria terrestre en un assaig de cobertura de sud a nord. L'any 1938 s'imprimiren, ${ }^{6}$ en «edició especial», els 847, 848, 822, 823 i 796 que, en versió definitiva no apareixerien fins al període 1945-1955. No considerem la sèrie L (1941-1966) del Servicio Geográfico del Ejército. Cal fer notar, tanmateix, que, el 1968, 1'Instituto Geográfico havia aconseguit completar la cobertura de l'estat.

L'Army Map Service nord-americà, des de 1964, formava un topogràfic propi del territori espanyol editat en sis colors (set, des de 1970) que no consideraré, però vull ponderar perquè, fet i fet, imposà una vertadera tirania a gairebé tota la cartografia mundial, inclosa l'espanyola que havia liquidat una època. L'any 1968, 1'Instituto Geográfico Nacional engegà la modernització dels seus productes, adoptant la projecció polièdrica UTM i el meridià de Greenwich, a base de fotografia aèria i minutes a 1/40.000. L'estalonament geodèsic començà a renovar-se el 1970 quan aparegué el MTN/25 com a sèrie complementària. Anys després, 1985, hom decidiria que cobrís tot el territori mitjançant restitució no analògica, sinó numèrica (Urteaga i Nadal, 2001). El 2001 es va completar la sèrie $i$, per això la considere en el meu comentari.

Els vint fulls del MTN $/ 25^{7}$ que ens afecten eixiren a la llum entre 1975 i 1997 en primera edició, cinc basats en un vol de 1970 (914 i 935); dotze en un altre de 1978 i els tres darrers (1996-1997; 848) en «informació digital». L'any 1975, n'eixiren tres, els més meridionals (935 I, II i III); el 1976, probablement

6. Alguns fulls estan editats en policromia, d'altres són monocroms i, fins i tot, n'hi ha amb l'altimetria incompleta. Aquests i els de «construcció aproximada» del Mapa Nacional del bàndol franquista, no els tindrem en compte en el repàs final.

7. La numeració conserva la pròpia del MTN/50, subdividit en quatre quarters: I (NW), II (NE), III (SW) i IV (SE). 
dos (914-II i IV?) en una primera embranzida. Calgué esperar dotze anys perquè és publicassen, canviant de model i presentació, els quatre següents (796 III i IV; 894 I i II). En seguiren, el 1989, vuit fulls més (822 IV; 823 I i III; 847 IV; 872 I, II i III i 893 IV). Després d'un parèntesi de set anys aparegueren, el 1996, el full 896 I en 1. a edició i, el 1997, els 848 I i III.

\section{EL RELLEU LITORAL I LA BATIMETRIA}

Comparar les sèries terrestre i nàutica porta a una deducció òbvia: les primeres atorguen més paper al relleu litoral i prelitoral mentre que les segones prefereixen la batimetria. Tanmateix, començaré per la cartografia més antiga.

La sèrie detallada de recalades, ports i sorgidors, ja comentada, és ara objecte de consideració. Tot i el seu caràcter arbitrari, recorreré a la numeració del catàleg hidrogràfic. La carta 284A Rada de Torrevieja (1883) es va convertir en Puerto de Torrevieja (1. ${ }^{\mathrm{a}}$ edició 1961, 2. ${ }^{\mathrm{a}}$ impressió 1965, corregida el 1972). Curiosament conserva les eminències següents: Monte Talentos 67, Guarda Salinas 19, Molinos de Poniente 29 i Casa de Gas 23, intactes de l'aixecament de 1881. Les sondes han estat esclarissades i enredonides; s'hi han afegit tres isòbates i el port que no exisitia vuitanta anys abans. El full 287A correspon a Ensenada de Benidorme (1877) de l'aixecament de R. Pardo que fa poc cas de les elevacions interiors i sí de Sierra Helada i de les mal anomenades Peñas del Arabí. El relleu, prou correcte, accentua les barrancades i els penya-segats amb una mena d'ombrejat fet d'hachures. El 288A reprodueix l'Ensenada de Altea (1878) a 1/18.600 ca on la faixa litoral empra el mateix procediment d'excel·lent gravat amb normals i hachures per al relleu que no ignora els camps conreats o els caixers de les rambles i dels barrancs. Una gran densitat de sondes coincideix amb isòbates de $-5 \mathrm{i}-10 \mathrm{~m}$. L'any 1941 encara estava vigent. La carta 289A Fondeaderos de Calpe (1878) incorpora el vèrtex Ifach 328. L'exquisit relleu incorporat pel gravat de la sèrie antiga malda per ser reproduït en una grollera imitació. Parle de la 3. ${ }^{a}$ impressió de 1971, amb sis isòbates entre -5 i $-50 \mathrm{~m}$, tot i que les sondes són prou més clares. 291A és el número que duia l'Ensenada de Morayra (1877), plànol corregit el 1973 i reeditat sobre una 2. impressió de 1965. N'és el resultat una rèplica deficient del gravat antic, afegint-hi unes quantes isòbates i llevant-ne més de la meitat de sondes, com al cas anterior. 292A, Ensenada y Puerto de Jávea (1961) vol ser una reproducció dibuixada del gravat de talla dolça (1879). En conec dues versions: una 3. impressió (1973) duu isòbates de $-5,-10,-20 \mathrm{i}-50 \mathrm{~m}$ i una 6. ${ }^{\mathrm{a}}$ (1985) incorpora una provatura de camins i edificis litorals, transposats del MTN. El 293A, titolat en ambdues versions Puerto de Denia (1879 i 1961), segueix a 1/10.000 ca la mateixa pauta amb la diferència que a la moderna els confusos placers tracten de ser resolts amb isòbates de $-1,-5,-10 \mathrm{i}-20 \mathrm{~m}$ (comprovat a la 3. impressió i correció de 
1973). A les dues versions figura com a senya Monte Mongó 761. El 729, Plano de la Rada de Villajoyosa (1878) a 1/10.000 ca donà peu a una transformació semblant a les anteriors en Puerto de Villajoyosa, corregida el 1961 i el 1972 $\mathrm{amb}$ un rònec pegat, després d'afegir-hi tres isòbates.

La sèrie gran $-\mathrm{a}$ escala $1 / 100.000 \mathrm{ca}-$ no ha tingut millor fortuna. $\mathrm{Al}$ cas del full 832, ja comentat, les cinc senyes dels relleus interiors (1888) es redueixen a dues en la versió de 1963: la Sierra de Callosa hi passa de 564 a 568 m d'altitud i la Sierra de Font Calent, de 421 a 426 m. Totes les altituds del full 833 (1888 i 1863) són replicades amb els mateixos rètols i xifres, encara que el relleu perspectiu s'hagi desdibuixat. Pel que fa a la carta 834 (1888 i 1963), s'hi troben lleugeres diferències: $\mathrm{M}^{\mathrm{te}}$ Mongó-Mongo, 761 i 753; Sierra SegariaSegaria, 514-508; Picacho de la Benguera-Picacho de la Benguera, 452 i 464; Mondúber-Mondúber, 850 i $851 \mathrm{~m}$ s.n.m. Tots els fulls reeditats amb el model acolorit afegeixen més isòbates, tot i dosificar les sondes i les indicacions de naturalesa del fons.

No hi ha cap full del Topogràfic clàssic que incorpore isòbates. Altra cosa són els de la sèrie MTN25 que, des de la primera edició, ${ }^{8}$ les inclouen sempre procedents de la respectiva carta nàutica. Solen ser les corresponents a $-5,-10$, $-20,-50 \mathrm{i}-100 \mathrm{~m}$. Cal anotar, de més a més, la figuració dels espigons, p.e., entre la platja de les Bovetes i les Marines de Dénia o la punta dels Molins (796 III), el símbol «roquedo» per als penya-segats (823 I i II, 848 II), el símbol de platja (872 III, 914 IV i 935 I). Sobta, però, que en aquest darrer full i el 914 II manque el símbol de dunes, allà on cobreixen l'extensió més notable del País Valencià.

El relleu terrestre comença a la línia costenca que era presa, obligatòriament des de 1884, de les cartes nàutiques. Això es va complir fins als anys 1970' quan la fotogrametria aèria va anar agafant primacia. Altrament, la tecnificació geodèsica havia avançat com pot deduir-se de la confrontació de les altituds assignades a les eminències prelitorals. Amb prou feines he trobat un parell de vèrtexs geodèsics comuns entre cartografia nàutica i terrestre, Ifach $(328 \mathrm{~m}$ carta 1878 i MTN 1952; 326 m MTN25) i Llorensa que va ballant entre 436 i $443 \mathrm{~m}$, amb quatre xifres diferents que devien respondre a operacions successives i d'administracions diverses. De la migrada coincidència documental cal deduir que les senyes marineres -escollides per raons peculiars- tenen poc en comú amb els vèrtexs topogràfics d'ordre divers. No ens hi podem entretenir, però remarquem que el Montgó que tenia $761 \mathrm{~m}$ d'altitud el 1888, ara figura $\mathrm{amb} 753$, tant a la carta nàutica com a la topogràfica. Igual trobem amb la xifra 1.436 del puig Campana. Les Sierras de Callosa i Font Calent de 1888 (564 i $421 \mathrm{~m}$ ) creixien un poc el 1963 (568 i $426 \mathrm{~m}$ ) d'acord amb el Topogràfic.

8. No duen isòbates el full 848 I ni el 848 II. 


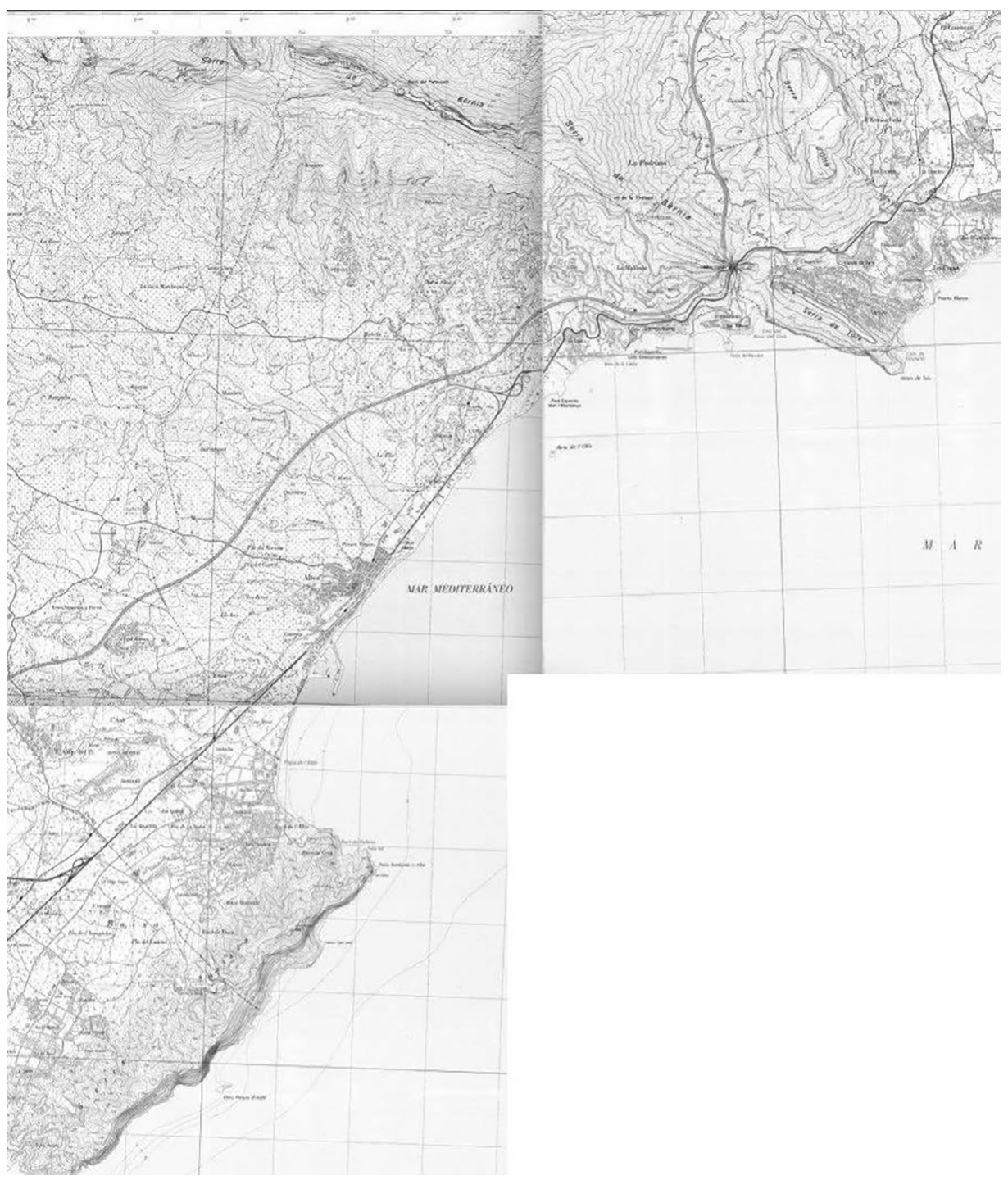

Figura 3. Composició dels tres fulls del MTN25, 848 I, II i III (1996 i 1997), Altea, Calp i Benidorm, aixecats amb informació digital.

Una repassada del MTN i del MTN25 permet verificar una vintena de vèrtexs de segon o tercer ordre que impliquen noves triangulacions o canvis de posició. És el cas de Faro de San Antonio (163 i $161 \mathrm{~m}$ ), Gavilá (29 i 28), Moncayo (104 i 105), Nao (116, 122 i 117), Santa Ana (21 i 22), Santa Pola (143 i 144), Sierra Helada (423 i 435), Torrejón (44 i 42), La Vieja (176 i 171), etc. 


\section{LA TOPONÍMIA COM A REACTIU}

Tot i que la koiné marinera de la nostra costa és catalana fins a Cartagena, els manobres de les cartes nàutiques del Vuit-cents ni els del Nou-cents en feren gaire cas. La influència de Vicente Tofiño, tant amb el Derrotero (1787) com amb les cartes, és responsable de la introducció de topònims espuris com el Arabi, ${ }^{9}$ en comptes de l'Albir, el Cabo de San Martín, en lloc del cap Martí. La vessant marítima de la serra Gelada s'ha dit, des que hi ha memòria escrita (Martines, 1991), les penyes de l'Albir (en el sentit de penya-segat o espadat); curiosament les cartes de 1877 conserven Faro del Albir i Punta del Albir... Una falsa llegenda explicaria la santificació del cap extrem de les Bètiques on certs aficionats a la història col·locaren un monestir. Tota la cartografia portolana, però, consigna Cap Martí o Caomartino que és la designació que donaven els mariners itàlics al pont de comandament de les galeres (Rosselló, 1997): en efecte, el cap vist des de la mar hi presenta una gran analogia.

Deixant a banda errades d'oïda o de transcripció -que òbviament afecten més una llengua desconeguda i menyspreada pels funcionaris oficials-, podríem agrupar els topònims esguerrats: els traduïts (o adaptats fonèticament) i els mal ortografiats. Sense ordre, en presente alguns dels primers: Vergel, Torre del Jarro, Cabo Blanco, Piedras del Dragón, Sierra Helada, C. ${ }^{\circ}$ Negro, El Caballo, Agua Amarga, C. ${ }^{\circ}$ de las Huertas, ${ }^{10} \mathrm{C} .{ }^{\circ}$ de la Nao. Benidorme (1877) és un cas flagrant d'adaptació que prové del Derrotero i C. ${ }^{\circ}$ Negrete (1876) va pel mateix camí.

Les deficiències ortogràfiques no poden estranyar tant. Cala Cañaret i Los Bañets, l'any 1888, tenien passada com Portichol i El Riachol, Torre Talayola i Los Pallés (els Pallers). Crec, així i tot, que cal insistir en dos casos: Cala Basetas apareix com a Cala Pasetes al Derrotero del segle xvIII, però seria massa demanar que escriguessen bé Bassetes i agrair-los que no posassen Balsitas o Balsicas... Ifak figura així al Derrotero i com a Ifach a la cartografia, quan el nom correcte era la penya de Calp; els puristes moderns han introduït penyal d'Ifac(h), allà on caldria dir i escriure penya de Calp o penya d'Ifac. Un híbrid com a Cabo Roig té justificació en l'ús habitual en terra castellanoparlant. No tots els topònims estan errats, ni de molt: La Pedrera (292A) va sobreviure, però l'han llevat a l'edició de 1961. El cas de Punta Prima (289A, 1883) és més xocant ja que a l'edició de 1961 hom va trobar que calia afegir-hi o Delgada!

A finals dels anys 1960 va començar una reivindicació revisora de la toponímia «oficial» a partir de les llengües perifèriques de l'estat, sobretot del català,

9. Tal volta hi va influir un nom autèntic de la costa eivissenca, punta Arabí, que Tofiño va transcriure Punta Araby.

10. A la carta 832 (1888) figura així com al MTN, però l'edició de la 832 (1963) ho va canviar a Cabo de la Huerta, topònim artificiós, també, però més justificat. 
que poc a poc, va calar endins. La reglamentació interna usada aleshores a l'organisme central obligava a traduir els genèrics, cosa que donava peu a hibridacions com Playa del Pinet o, el més destrellatat, Punta Este del Mojó [sic]. Posteriorment, les coses han anat millorant.

Si els fulls 872 Alicante, editats el 1940 i 1966, són deplorables, la versió del MTN25 (fulls I, II i III) es podria considerar més o menys correcta. La immediata 893, tot i publicada el 1989, és coberta d'una mala i desigual toponímia, qualitat que també manca als fulls 894 I i III. El Alted s'ha convertit en El Altet: no gosaren arribar a un correcte l'Altet. Devia ser massa per a un aeroport. Els fulls 914 i 915 no s'han corregit gaire i del 935, editat el 1976, no es podria esperar un resultat diferent. Els quarters eixits a llum els anys 1988 i 1989 solen ser més coherents, encara que hom puga trobar contradiccions com la coexistència de Suertes del Mar i Sorts de la Mar (796 IV) o una Marcheleta (la Marjaleta) al 822 IV. La sèrie digital -del segle XXI- permet albirar esperances. ${ }^{11}$

$\mathrm{Al}$ quadre següent he reunit exemples de l'evolució d'uns quants topònims gràcies a la conscienciació dels tècnics de l'Instituto Geográfico.

\begin{tabular}{|l|l|l|}
\hline MTN 823 1. ${ }^{a}$ ed. (1945) & MTN25 823 I i III (1989) & MTN sèrie digital (2007) \\
\hline Cueva de Agua Dulce & & Cova de l'Aiguadolce \\
\hline Cueva Tallada & Cova Tallada & Cova Tallada \\
\hline Cabo San Antonio & Cabo de San Antonio & Cap de Sant Antoni \\
\hline Aduanas & La Duana & Aduanas \\
\hline Punta del Español & Punta de l'Espanyol & Punta de l'Espanyol \\
\hline Montañar & Montanyar & Muntanyar 2 \\
\hline Cabo San Martín & Cabo de San Martín & Cap San Martí \\
\hline Portichol & Portixol & Portixol \\
\hline Cabo Negro & Cap Negre & Cap Negre \\
\hline Cabo de la Nao & Cabo de la Nao & Cap de la Nao' \\
\hline Isla del Descubridor & Isla del Descubridor & Illa del Descubridor \\
\hline Morra de la Branca & Morro de la Blanca & Morro de la Branca \\
\hline Morra del Roabit & Morro del Roabit & Morro del Roabit \\
\hline Cala los Tiestos & Cala los Tiestos & Cala dels Testos \\
\hline Islote los Pegados & Islote de los Pegados & Illot dels Pegats \\
\hline Morro del Tamarit & Morro del Tamarit & Morro del Tamarit \\
\hline
\end{tabular}

11. Hi haurien de col-laborar els municipis que tenen competències per resoldre la seua denominació «oficial» amb l'estalonament de la Generalitat.

12. Com se sol dir, el cap de la Nau no és l'avançada oriental del País Valencià. Ho és la barra de la Ferradura: 0. ${ }^{\circ} 14$ ' 6" E. 
Correcte seria Cova de l'Aiguadolça, Les Duanes, El Muntanyar, Cap Martí, El Portitxol, Cap de la Nau, Illa del Descobridor, Morra de la Branca, Morra del Roàbit.

\section{Conclusió}

Tant la sèrie de les cartes nàutiques o hidrogràfiques com les del Mapa Topográfico Nacional pateixen una malatia crònica: la manca de criteris uniformes al llarg de la seua prolongada història. Per una banda, la unitat o coordinació somiada per Felip Bauzà en començar el segle XIX no ha existit mai, cosa que ha afectat molt les nostres terres; per l'altra, la manca de criteris estables en el contingut cartogràfic o en l'expressió semiològica i particularment en la retolació toponímica ha repercutit en un vertader desgavell comunicatiu que en l'últim quart de segle xx comença a dissoldre's.

El ram hidrogràfic fou el primer en organitzar-se i, pel que fa al litoral valencià, assolí una sòlida maduresa a final del Vuit-cents, gràcies a l'empenta d'uns oficials comandats per Rafael Pardo de Figueroa i secundats per uns experts dibuixants i gravadors. Són seues la sèrie de cartes a 1/100.000 i les més detallades de ports, recers i recalades de rigorosa batimetria i que especifiquen la naturalesa dels fons. La comparança entre els documents impresos devers 1880 i els produïts a partir de 1963 és rònegament anorreadora: de vertaderes obres d'art, passem a còpies infantiloides o resultats absolutament anodins on s'han afegit isohipses sense to ni so o dades terrestres no constants -les senyes donen alçades contradictòries- mentre minva la pròpiament nàutica. Un abisme.

L'execució del Mapa Topográfico Nacional va durar prop d'un segle, cosa que explica les substancials diferències que hi ha entre els fulls primerencs i els més tardans; els mitjans tècnics d'obtenció de dades i de reproducció progressaren força; hi contribuí també la rivalitat entre dirigents militars i civils que encapçalaven l'Instituto Geográfico segons comandassen els conservadors o els progressistes i una guerra civil enmig. La nostra principal ciutat, Alacant, va ser escollida, el 1872, per estalonar el datum altimètric de la cartografia espanyola, un cop descartada Cartagena. La sèrie principal del MTN fou publicada entre 1928 i 1955.

Una primera mentalització, la dècada dels 1960, dels dirigents de l'Instituto per millorar la toponímia topava amb inconvenients tan ridículs com que no disposaven d'accents greus a les plantilles de gravat! Poc a poc aniria imposant-se el topònim com a unitat lingüística i cultural i uns procediments per a una recollecció metòdica i una generalització proporcional, segons l'escala. Amb la sèrie MTN25 els fulls de la qual (1975-1997) hem considerat s'ha avançat molt des de tots el punts de vista. Encara, desitgem, ulteriors millores. 


\section{BIBLIOGRAFIA}

CAno, José María (2003): II. Catálogo de las Cartas náuticas publicadas. Ministerios de Defensa y Fomento. Madrid, 424 pp.

González, Francisco José i Martín-Merás, Luisa (2003): La Dirección de Trabajos Hidrográficos (1797-1908). I. Ministerios de Defensa y Fomento. Madrid, 252 pp.

Martines, J. (1991): «Els llocs vora mar de l'Albir (l'Alfàs del Pi, La Marina. País Valencià)». A sol post, 2: 193-218.

Rosselló, Vicenç M. (1997): «Els italianismes de les cartes portolanes mallorquines». Estudis de llengua i literatura en honor de Joan Veny. I. Publicacions de l'Abadia de Montserrat. Barcelona, cf. pp. 39-62.

Rosselló, Vicenç M. (2008): Cartografia històrica dels Països Catalans. Universitat de València - Institut d'Estudis Catalans. València, 402 pp.

ToFiño, Vicente (1787): Derrotero de las costas de España en el Mediterráneo. Imprenta de la viuda de Ibarra. Madrid, LVIII + 227 pp.

Urteaga, Luis i NADAL, Francesc (2001): Las series del mapa topográfico de España a escala 1:50.000. Instituto Geográfico Nacional. Madrid, 397 pp. 